\title{
Inline monitoring of high cell density cultivation of Scenedesmus rubescens in a mesh ultra-thin layer photobioreactor by photon density wave spectroscopy
}

\author{
Michael Sandmann ${ }^{1 *}$, Marvin Münzberg ${ }^{2}$, Lena Bressel², Oliver Reich² and Roland Hass ${ }^{2,3}$
}

\begin{abstract}
Objective: Due to multiple light scattering that occurs inside and between cells, quantitative optical spectroscopy in turbid biological suspensions is still a major challenge. This includes also optical inline determination of biomass in bioprocessing. Photon Density Wave (PDW) spectroscopy, a technique based on multiple light scattering, enables the independent and absolute determination of optical key parameters of concentrated cell suspensions, which allow to determine biomass during cultivation.

Results: A unique reactor type, called "mesh ultra-thin layer photobioreactor" was used to create a highly concentrated algal suspension. PDW spectroscopy measurements were carried out continuously in the reactor without any need of sampling or sample preparation, over 3 weeks, and with 10-min time resolution. Conventional dry matter content and coulter counter measurements have been employed as established offline reference analysis. The PBR allowed peak cell dry weight (CDW) of $33.4 \mathrm{~g} \mathrm{~L}^{-1}$. It is shown that the reduced scattering coefficient determined by PDW spectroscopy is strongly correlated with the biomass concentration in suspension and is thus suitable for process understanding. The reactor in combination with the fiber-optical measurement approach will lead to a better process management.
\end{abstract}

Keywords: Photon density wave spectroscopy, Multiple light scattering, Process analytical technology, Fiber-optical spectroscopy, Mesh ultra-thin layer photobioreactor

\section{Introduction}

Algae are one of the most promising candidates for solving the problem of nowadays need for renewable energy and sustainable food [1-7]. In comparison to heterotrophic production systems like yeasts, phototrophic production of algae still needs significant improvement to operate cultivations at high cell densities. To close this gap, different types of photobioreactors (PBR) were

\footnotetext{
${ }^{*}$ Correspondence: sandmann@hs-nb.de

1 University of Applied Sciences Neubrandenburg, Brodaer Straße 2,

17033 Neubrandenburg, Germany

Full list of author information is available at the end of the article
}

devised in the past but up-scaling into an industrial scale is still a challenge and the initial investment and operating costs are still high [8]. The optimization of PBR in terms of light harvest, nutrient supply, or gas exchange is of utmost importance for improvement of the biomass production efficiency.

One potential approach to monitor the outcome of PBR design-changes, is the implementation of suitable inline process analytical technologies (PAT), providing access to algal growth kinetics also at very high cell concentrations. A common approach is to monitor the process state either by dry matter content determination as established offline analysis or by optical density 
probes [9-11]. Offline analyses use aliquots of the cell culture which often increases the risk of contamination with other microbes, is time consuming and thus gives strongly delayed process information. Due to multiple light scattering that occurs inside and between cells, quantitative optical inline determination of biomass by, e.g., optical density probes, is still a major challenge [11]. In this study, an advanced optical method, called Photon Density Wave (PDW) spectroscopy was applied as inline tool to evaluate if monitoring of algal growth in a high cell density cultivation is possible and to which extend it reflects results of accepted reference techniques. PDW spectroscopy, a technique based on multiple light scattering, enables the independent and absolute determination of optical key parameters of concentrated suspensions [12]. It has been recently applied to several chemical, physical, and biotechnological processes, but has not yet been implemented in algae cultivation [13-19]. High algal cell concentrations have been obtained by a socalled "mesh ultra-thin layer (MUTL) PBR". The unique reactor design was recently described [20-22]. However, detailed knowledge about, e.g., multiphase-fluid dynamics, light penetration, or effects of the specialized geometry on algal biology is still missing. Here, this PBR was used to generate a high cell density cultivation with a CDW of $33.4 \mathrm{~g} \mathrm{~L}^{-1}$. PDW spectroscopy was used to investigate biomass dynamics over time in this novel type of PBR. Aim of this study is the investigation of the suitability of PDW spectroscopy for inline biomass monitoring during high cell density cultivations of algae.

\section{Main text \\ Experimental section \\ Photobioreactor}

Algal cultivation was performed under greenhouse conditions in a prototype MUTL PBR at the IGV GmbH (Nuthetal, Germany). The experiment has been executed during August and September in 2012. The greenhouse was used as transparent shell to protect a collection of different PBR against harsh weather conditions and to prolong the growth period of the algae. Different to the MUTL PBR, the greenhouse itself was not illuminated or temperature controlled. A scheme of the PBR is displayed in Fig. 1A and the adapter for the PDW spectroscopy process probe is shown in Fig. 1B.

Briefly, the configuration of the PBR used in this work consists of 40 vertically stacked horizontal polymer nets with an average distance of $0.05 \mathrm{~m}$ between them. The polymer nets are enclosed in a $2.5 \mathrm{~m}$ high, transparent polymethyl methacrylate housing, occupying a footprint area of $4.84 \mathrm{~m}^{2}$. The water-cooled double bottom of the reactor is coupled to an external cooling device. The PBR is equipped with a continuously working recirculation loop to pump algal suspension from the sink to the top of the PBR from which the suspension is sprayed by spiral jet nozzles on the polymer nets. Such nozzles need a

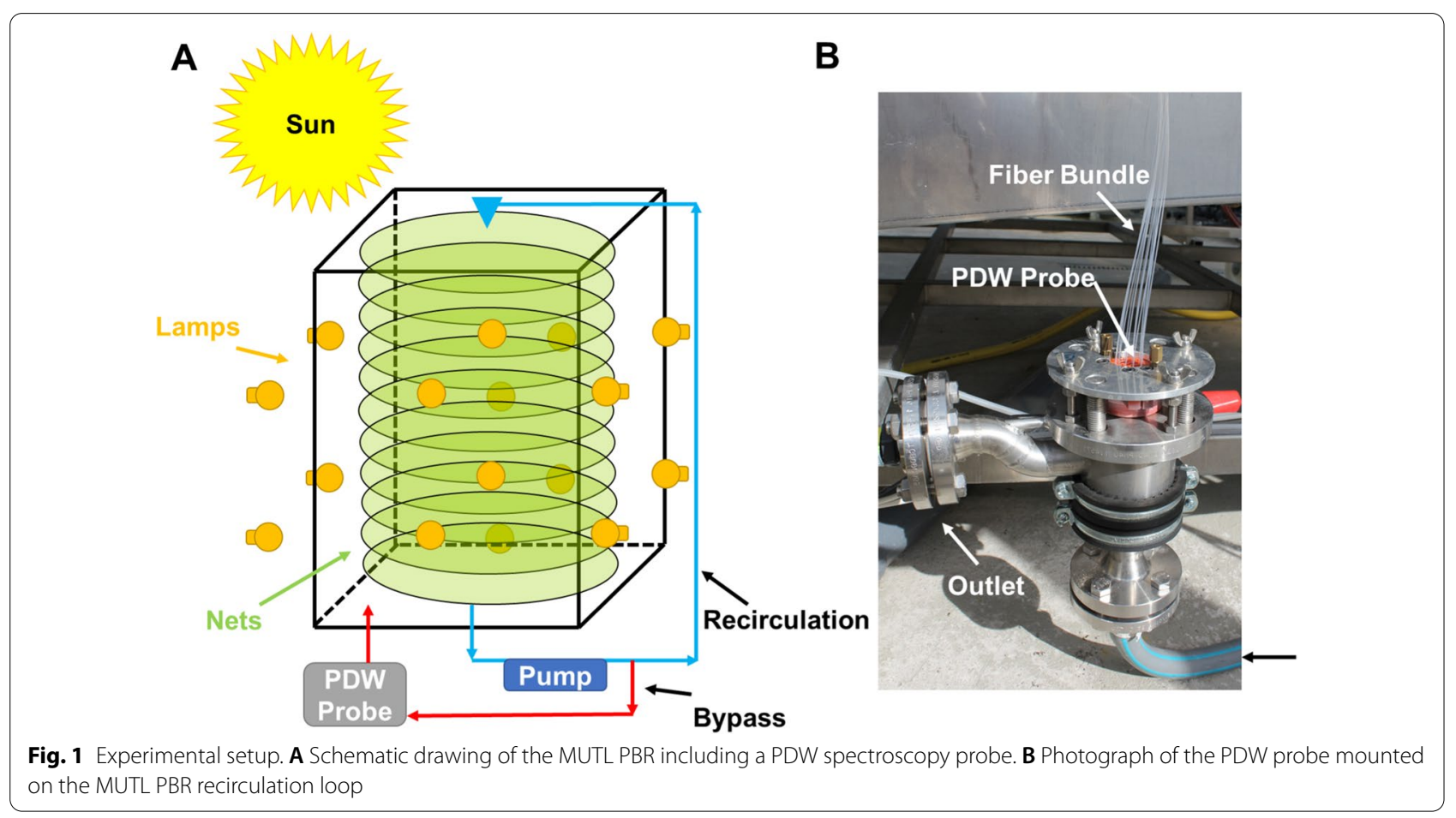


relatively high liquid pressure of 1 to 3 bar but have a high clog-resistance [22]. During their movement through the stack of nets, cells are exposed to the incident light and the surrounding gas phase. The PDW spectroscopy probe is inserted in a special flow-cell implemented in the recirculation loop (Fig. 1B). Nitrate content was measured during algal growth with the 'Nitrate Cell TestKit in seawater' from WTW (Xylem Analytics Germany Sales GmbH \& Co. KG, WTW, Weilheim, Germany) and a concentrated solution of all five macronutrients were added if around $40 \%$ of the starting concentration of nitrate was reached during the experiment. This procedure was based on the assumption that all macro constituents will deplete in parallel. During the cultivation, biomass growth was supported through additional 16 high pressure sodium lamps with $400 \mathrm{~W}$ power each. The lamps have been distributed on all four sides of the PBR. The growth experiment was executed for 21 days.

\section{Culturing of Scenedesmus rubescence}

Scenedesmus rubescence strain SAG 5.95 was obtained from the SAG Culture Collection of Algae (Göttingen, Germany). The preculturing was done in ten lab-scale bubble columns (1.8 L suspension volume each) under continuous light with a light intensity of $120 \mu \mathrm{mol}$ photons $\mathrm{m}^{-2} \mathrm{~s}^{-1}$ at $25{ }^{\circ} \mathrm{C}$ and $3 \% \mathrm{CO}_{2}[\mathrm{v} / \mathrm{v}]$ in a synthetic growth media called $1 / 2$ Tamiya [23, 24]. Further up-scaling for production of the inoculum culture for the cultivation experiment within the MUTL-PBR was done in a $90 \mathrm{~L}$ tubular PBR with the same growth media and an initial CDW of $0.3 \mathrm{~g} \mathrm{~L}^{-1}$. The $90 \mathrm{~L}$ PBR was already located in the same greenhouse as the MUTL-PBR. The cells have been prevented from heat-shock by an automated water-cooling by sprinkling. After reaching the beginning of stationary growth phase a part of the cell suspension from the $90 \mathrm{~L}$ PBR was used to inoculate the MUTL-PBR. Pre-culture was performed under axenic conditions. In the further up-scaling and the MUTL experiment this cannot be guaranteed anymore. To keep microbial contaminations on a minimal level all large-scale PBR have been thoroughly cleaned with aqueous sodium peroxide solution [22].

\section{Quantification of cell size and cell concentration}

Cell size and cell concentration were determined by offline measurements (MULTISIZER 3, Beckman Coulter, Krefeld, Germany) once or twice per day [25, 26]. An important parameter that can be measured by this kind of device is the total cellular volume [(given in cubic micrometers $\left(\mu \mathrm{m}^{3}\right)$ per milliliter of suspension)]. It is defined as the sum of all cellular volumes present in $1 \mathrm{~mL}$ of suspension, is a measure of the biomass or wet-weight concentration of the cells present in suspension and has been widely applied in other studies $[27,28]$.

\section{Determination of the cell dry weight}

Determination of CDW was done gravimetrically once or twice per day. Briefly, 5 to $10 \mathrm{~mL}$ aliquots from the cell suspension were centrifuged at $3000 \times g$ for $10 \mathrm{~min}$ in preweighed glass tubes. The pellet was afterwards washed with deionized water and then dried at $105{ }^{\circ} \mathrm{C}$ for $24 \mathrm{~h}$. Prior to the weight measurements, the hot glass tubes were cooled to room temperature in a desiccator. The weight difference corresponds to the dry matter content of the cell suspension.

\section{Photon density wave spectroscopy}

A PDW spectrometer features an intensity modulated laser as light source. By an optical emission fiber, the laser light is guided into a fiber-optical probe being implemented in a special flow cell [29] in the recirculation loop. The fiber end acts as point-like light source. Due to multiple light scattering and absorption a PDW is created within the algae suspension. Further detection fibers in the probe collect light from the PDW and guide it back to the detector inside the spectrometer. Changes to phase and amplitude of the PDW are characterized by a vector network analyser within the spectrometer. These changes give access to the optical coefficients of the algae suspension.

Here, a self-constructed PDW spectrometer (commercial versions available by PDW Analytics $\mathrm{GmbH}$, Potsdam, Germany) was applied [29] and a measurement wavelength of $906 \mathrm{~nm}$ with modulation frequencies from 10 to $810 \mathrm{MHz}$ was used. To characterize the PDW as function of distance between emission and detection fiber, a fiber-optical probe consisting of one central emission fiber and 12 surrounding detection fibers was constructed [29]. The distances ranged from $9.47 \mathrm{~mm}$ to $20.38 \mathrm{~mm}$. For raw data analysis, a refractive index of $n=1.3264$ at $906 \mathrm{~nm}$ was used (refractive index of water, obtained as described in [13]). PDW spectroscopy measurements were carried out continuously with 10-min time resolution.

\section{Results}

Results of the reference analysis

Development of the algal culture in the MUTL PBR is shown in Fig. 2A. Algal cells showed a lack phase of 2 to 3 days and afterwards started strong biomass growth with nearly linear increase of dry matter content in the cell suspension. Close to the end of the lack phase the artificial light was continuously switched on for the rest of the experiment (Fig. 2A). Mean growth rate was comparatively high $\left(2.39 \mathrm{~g} \mathrm{~L}^{-1}\right.$ day $\left.^{-1}\right)$ during 


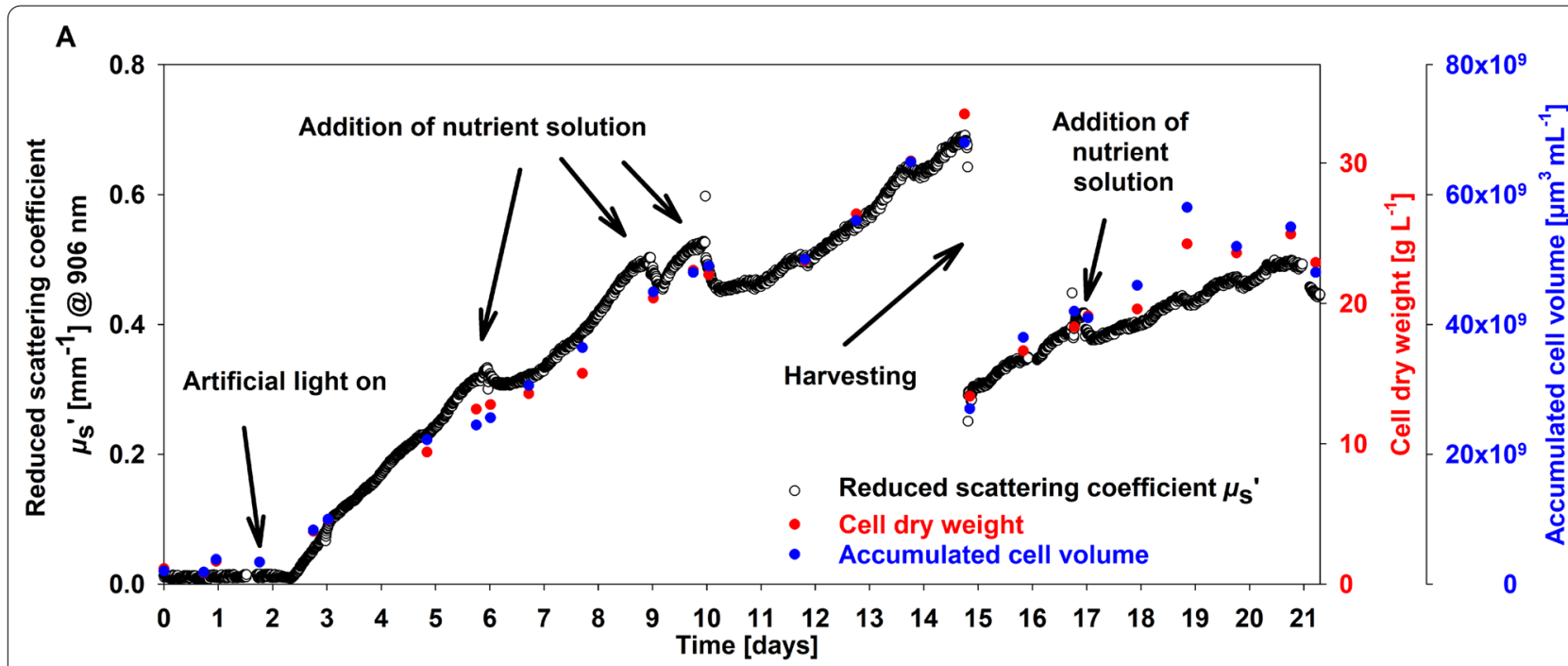

B

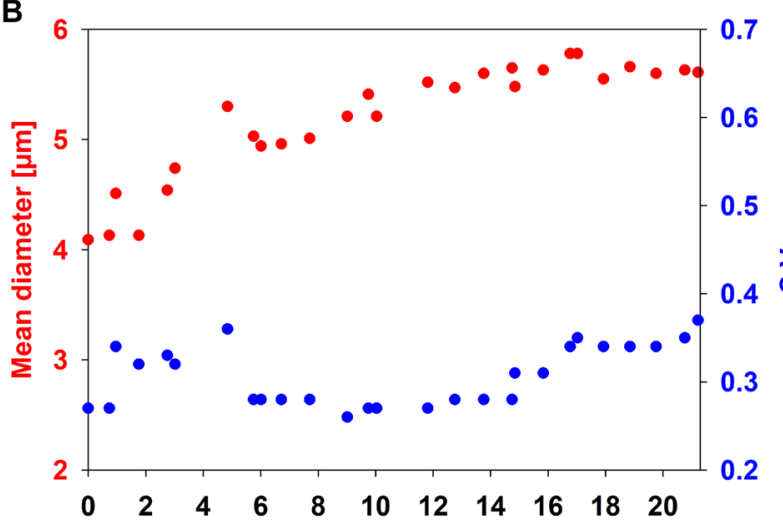

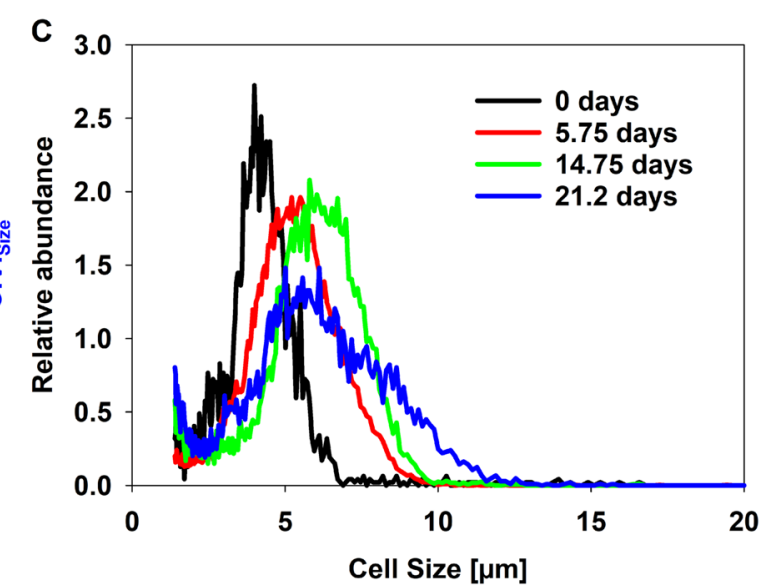

Fig. 2 Culture characterization over time. A Development of biomass related parameters. B Mean diameter and coefficient of variation (CV) as a measure for the width of the cell size distribution. $\mathbf{C}$ Selected cell size distributions determined by Coulter counter (sample time in legend)

first 14 days of growth. At day 14 the cell suspension was partly harvested and refilled with fresh culture media (Fig. 2A) and afterwards the reactor was running for additional 6 days. At different timepoints, concentrated solution of macro nutrients was added to the cell culture (Fig. 2A). The analysis of total cellular volume has been used as additional reference technique. It exhibits a very similar development like the dry matter content. Based on Coulter counter measurements, a deeper analysis of the population dynamics of the algal cells can be obtained (Fig. 2B). During cultivation, cells increased their mean diameter from approximately 4.0 to $5.6 \mu \mathrm{m}$ (Fig. 2B). Also, the coefficient of variation $\left(\mathrm{CV}_{\text {Size }}\right)$ of the cell size is displayed. The $\mathrm{CV}_{\text {Size }}$ is a relative measure for the widths of a distribution and can be used to quantify the cell-to-cell heterogeneity inside a cell population. The $\mathrm{CV}_{\text {Size }}$ increased from 0.27 to 0.37 , which means an increased heterogeneity. This is visible also in the cell size distributions (Fig. 2C). Cell size ranged between 2 to $12 \mu \mathrm{m}$ in diameter, which is similar to other Scenedesmus species [24].

\section{Results of PDW spectroscopy and correlation with the reference analysis}

PDW spectroscopy determined the optical coefficients with high temporal resolution, unattended, and without sampling. Generally, $\mu_{\mathrm{s}}{ }^{\prime}$ at $906 \mathrm{~nm}$ indicates the same dynamics as function of time as both reference analyses (Fig. 2A). Based on $\mu_{\mathrm{s}}{ }^{\prime}$, dilution effects from the addition of concentrated media component solution and the harvesting procedure can be visualised with high time resolution and even growth rates are obtained in nearly real-time (Additional file 1: Figure S1). However, at low CDW PDW spectroscopy is not able to provide reliable 
optical coefficients due to too low turbidity of the algae suspension. $\mu_{\mathrm{s}}{ }^{\prime}$ values have been correlated with both corresponding reference analyses, indicating a linear correlation with $R^{2}=0.9726$ against CDW and $R^{2}=0.9561$ against Coulter counter data (Fig. 3). Correlation of both reference analyses resulted in $R^{2}=0.9895$ (Additional file 1: Figure S2).

\section{Discussion}

Quantitative optical inline spectroscopy is still a challenge especially in concentrated biotechnical process [30]. One reason is a parallel occurrence of light absorption and multiple light scattering. The aim of the recent work was to investigate if PDW spectroscopy is applicable as inline tool for monitoring of algal growth in a high cell density cultivation. As parameter of relevance, the reduced scattering coefficient should correlate with different offline reference methods. Photoautotrophic growth of algal cells has been investigated in a very specialized photobioreactor called MUTL (Fig. 1). In comparison to classical PBRs, MUTL-PBRs exhibit significantly higher peak CDW and growth rates. This was shown in three different references, but with a strong spread of the exactly reached peak CDW ranging from 6.6 to $40 \mathrm{~g} \mathrm{~L}^{-1}$ [20-22]. In this study, the MUTL-PBR was used to culture high cell densities up to $33.4 \mathrm{~g} \mathrm{~L}^{-1}$. Conventional offline techniques have been used to describe growth characteristics of the culture. For comparison, inline measurements by PDW spectroscopy were performed directly in the cell culture. PDW spectroscopy provided reduced scattering coefficients $\left(\mu_{\mathrm{s}}\right)$ of the algal suspension, with peak values of approx. $0.7 \mathrm{~mm}^{-1}$ at $906 \mathrm{~nm}$. In this experiment, $\mu_{\mathrm{s}}{ }^{\prime}$ is found to be strongly correlating with both applied reference analyses (Figs. 2 and 3). PDW spectroscopy was able to measure fast dynamics, e.g., harvesting of the cells and influences of nutrient addition. In comparison to offline analyses, PDW spectroscopy was able to continuously monitor fast changes in the cell suspension, without any need for sampling or sample preparation and with high temporal resolution. It has been shown that also growth rates derived from $\mu_{\mathrm{s}}{ }^{\prime}$ can be calculated (Additional file 1: Figure S1). As presented, the addition of the nutrient solution was based on offline measurements of the nitrate content within the media. The measurements were done only once or twice per day, are labor-intensive and result in a nutrient feed with time delay. A feed strategy that will be directly coupled with the continuously measured growth rate by PDW should be used to establish a realtime adjustment of nutrient feeding. This might result in even better growth rates of the MUTL PBR and should be proven in future experiments. Putative adverse effects that might interfere with the PDW measurements are minor. This was shown through the thorough comparison of the PDW signals with two independent and accepted reference analyses throughout the complex growth trajectory of the cell culture. The comparison resulted in coefficient of determination $\left(R^{2}\right)$ close to 1 (Fig. 3).

Implementing such a highly advanced fiber-optical technology was never executed before in a PBR. Additionally, up to now the recent work included the most detailed analysis of the trajectory of algal growth in the novel MUTL PBR type. In the past it has been

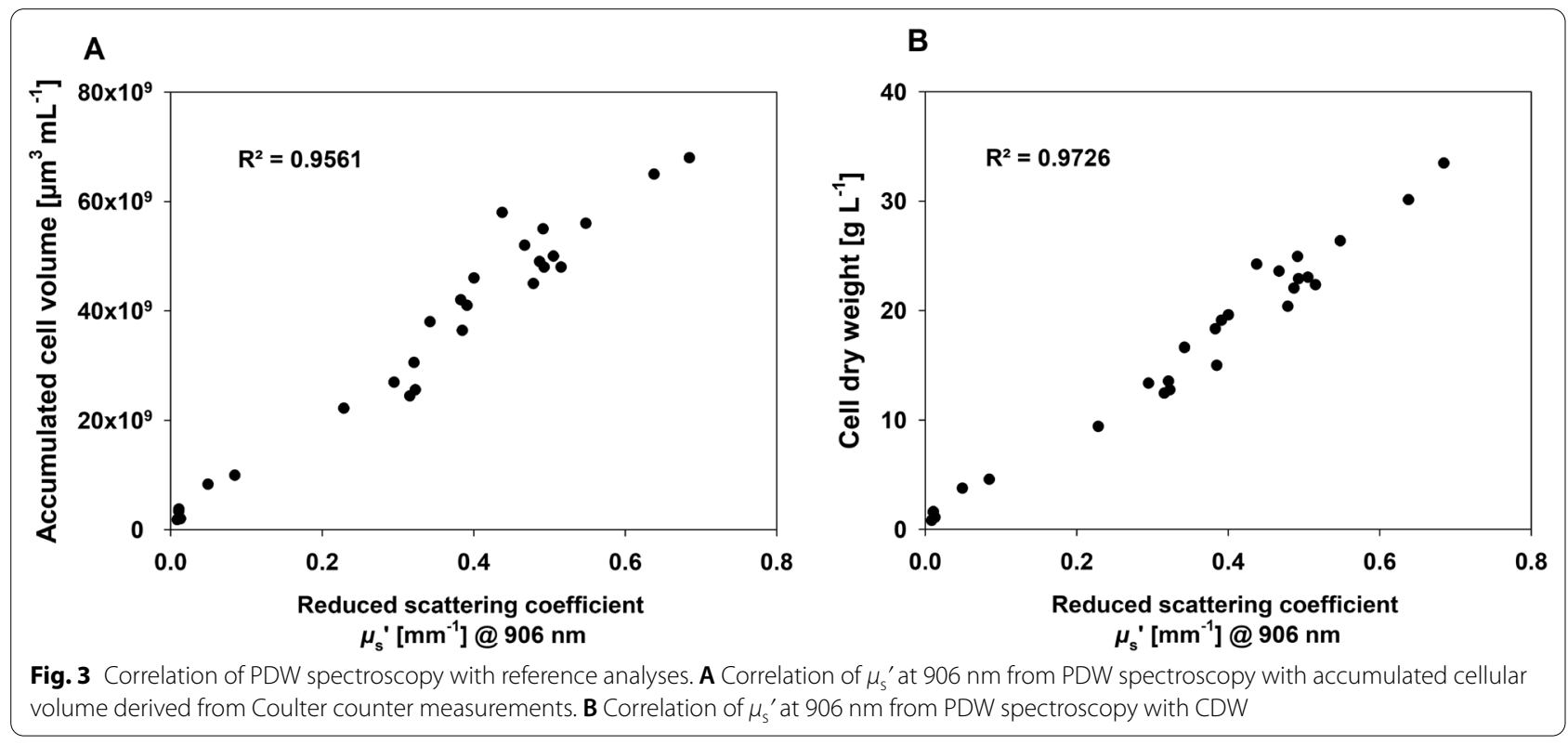


shown that PDW spectroscopy was able to monitor dynamics in processes in much more concentrated suspensions or dispersions. Examples are, e.g., concentrated nanoparticle suspensions with $\mu_{\mathrm{s}}{ }^{\prime}$ of up to $20 \mathrm{~mm}^{-1}$ or emulsification processes with $\mu_{\mathrm{s}}{ }^{\prime}$ of more than $5 \mathrm{~mm}^{-1}$ [13]. In a biotechnological production of polyhydroxyalkanoate (PHA), CDW of $40 \mathrm{~g} \mathrm{~L}^{-1}$ have been reached corresponding to $\mu_{\mathrm{s}}{ }^{\prime}$ of $2 \mathrm{~mm}^{-1}$ [19]. It can be concluded that the reduced scattering coefficient as determined by PDW spectroscopy seems to be a suitable measure for $\mathrm{CDW}$ in diverse biotechnological processes, including high cell density algal growth. Additionally, $\mu_{\mathrm{s}}{ }^{\prime}$ can be used to calculate growth rates in nearly real-time, enabling process monitoring even in highly concentrated suspensions. Furthermore, the determined optical parameters of algal cells can be used in future approaches to model light penetration within PBRs which is expected to be a key to enhance reactor performance $[31,32]$. Thus, there is a high potential for PDW spectroscopy to be used for advanced process monitoring, process control, and to ensure a better process understanding in concentrated biotechnological suspensions.

\section{Limitations}

- Data from reference analysis were taken without replicates.

- Cultivation reproducibility with respect to CDW of 33.4 $\mathrm{g} \mathrm{L}^{-1}$ was not tested. However, focus here was on suitability of PDW spectroscopy for inline biomass monitoring.

- Raw data analysis for PDW spectroscopy took assumptions into account, referring to the refractive index and volume fraction of cells, respectively.

- The flow cell for PDW spectroscopy probe implementation was not optimized for reduction of shear forces onto cells. Thus, structural damage might have been induced.
Additional file 1: Figure S1. Growth rate (GR $R_{\text {PDW,in-line) }}$ ) of the algal cells based on $\mu_{s}^{\prime}$. Growth rate is based on the slope within the time increments $\left(\mu_{s}^{\prime}\right.$ 'time). Original data from $\mu_{s}{ }^{\prime}$ was smoothed before analysis with a simple moving average based on 31 data points. Plotting of growth rate is done with simple moving average based on 11 data points. $\mu_{\mathrm{s}}$ is plotted as unsmoothed data as given in figure $2 \mathrm{~A}$. Figure $\mathbf{S 2}$. Correlation of both reference analyses.

\section{Acknowledgements}

We like to acknowledge IGV GmbH, especially Thomas Wencker and Peter Waldeck, for the possibility to use their photobioreactors for our measurements as well as Till Meiling and Carsten Hille for experimental help.

\section{Authors' contributions}

$\mathrm{MS}, \mathrm{MM}, \mathrm{LB}, \mathrm{OR}$, and $\mathrm{RH}$ conducted the experiment, collected data, and analyzed the data set. LB and OR developed the control and data processing software of the PDW spectrometer. OR gathered funds and supervised the entire experiments. MS and RH prepared the manuscript. All authors read and approved the final manuscript.

\section{Funding}

Open Access funding enabled and organized by Projekt DEAL. We like to thank the "Centre for Innovation Competence" innoFSPEC of the BMBF (Grant 03Z2AN12) and the Land Brandenburg for the project SEMIRAMIS (ILB project number 80139585) for financial support.

\section{Availability of data and materials}

The original datasets and other miscellaneous materials related to the investigation are available upon reasonable request to the corresponding author.

\section{Declarations}

Ethics approval and consent to participate

Not applicable.

\section{Consent for publication}

Not applicable.

\section{Competing interests}

The authors declare that they have no competing interests.

\section{Author details}

${ }^{1}$ University of Applied Sciences Neubrandenburg, Brodaer Straße 2, 17033 Neubrandenburg, Germany. ${ }^{2}$ Physical Chemistry-innoFSPEC Potsdam, Institute of Chemistry, University of Potsdam, Am Mühlenberg 3, 14476 Potsdam, Germany. ${ }^{3}$ PDW Analytics GmbH, Geiselbergstr. 4, 14476 Potsdam, Germany.

Received: 30 September 2021 Accepted: 1 February 2022 Published online: 15 February 2022

\section{Abbreviations}

PDW: Photon density wave; CDW: Cell dry weight; MUTL: Mesh ultra-thin layer; PAT: Process analytical technology; PBR: Photobioreactor; Min: Minute; CV: Coefficient of variation; GR $R_{\text {PDW,inline: }}$ Growth rate based on $\mu_{s}$.

\section{Supplementary Information}

The online version contains supplementary material available at https://doi. org/10.1186/s13104-022-05943-2.
References

1. Levasseur W, Perré P, Pozzobon V. A review of high value-added molecules production by microalgae in light of the classification. Biotechnol Adv. 2020;41:107545.

2. Sandmann M, Schafberg M, Lippold M, Rohn S. Analysis of population structures of the microalga Acutodesmus obliquus during lipid production using multi-dimensional single-cell analysis. Sci Rep. 2018;8:6242.

3. Wells ML, Potin P, Craigie JS, Raven JA, Merchant SS, Helliwell KE, Smith AG, Camire ME, Brawley SH. Algae as nutritional and functional food sources: revisiting our understanding. J Appl Phycol. 2017;29:949-82.

4. Arun J, Gopinath KP, Rajan PSS, Felix V, Monica MJ, Malolan R. A conceptual review on microalgae biorefinery through thermochemical 
and biological pathways: bio-circular approach on carbon capture and wastewater treatment. Bioresour Technol Rep. 2020;11:100477.

5. Smetana S, Sandmann M, Rohn S, Pleissner D, Heinz V. Autotrophic and heterotrophic microalgae and cyanobacteria cultivation for food and feed: life cycle assessment. Bioresour Technol. 2017;245:162-70.

6. Sevgili H, Sezen S, Yllayaz A, Aktaş Ö, Pak F, Aasen IM, Reitan KI, Sandmann M, Rohn S, Turan G, Kanyllmaz M. Apparent nutrient and fatty acid digestibilities of microbial raw materials for rainbow trout (Oncorhynchus mykiss) with comparison to conventional ingredients. Algal Res. 2019:42:101592.

7. Hensel B, Jakop U, Scheinpflug K, Schröter F, Sandmann M, Mühldorfer K, Schulze M. Low temperature preservation: influence of putative bioactive microalgae and hop extracts on sperm quality and bacterial load in porcine semen. Sustain Chem Pharm. 2021;19:100359.

8. Gupta PL, Lee SM, Choi HJ. A mini review: photobioreactors for large scale algal cultivation. World J Microbiol Biotechnol. 2015;31:1409-17.

9. Sonnleitner B, Locher $\mathrm{G}$, Fiechter A. Biomass determination. J Biotechnol. 1992;25:5-22.

10. Gregory ME, Thornhill NF. The effects of aeration and agitation on the measurement of yeast biomass using a laser turbidity probe. Bioprocess Eng. 1997;16:339-44.

11. Münzberg M, Hass R, Khanh DDN, Reich O. Limitations of turbidity process probes and formazine as their calibration standard. Anal Bioanal Chem. 2017:409:719-28.

12. Bressel L, Hass $R$, Reich $O$. Particle sizing in highly turbid dispersions by photon density wave spectroscopy. J Quant Spectrosc Radiat Transf. 2013;126:122-9.

13. Hass R, Münzberg M, Bressel L, Reich O. Industrial applications of photon density wave spectroscopy for in-line particle sizing. Appl Opt. 2013;52:1423-31.

14. Vargas Ruiz S, Hass R, Reich O. Optical monitoring of milk fat phase transition within homogenized fresh milk by photon density wave spectroscopy. Int Dairy J. 2012;26:120-6.

15. Werner $P$, Münzberg $M$, Hass $R$, Reich $O$. Process analytical approaches for the coil-to-globule transition of poly ( $\mathrm{N}$-isopropylacrylamide) in a concentrated aqueous suspension. Anal Bioanal Chem. 2017:409:807-19.

16. Hartwig A, Hass R. Monitoring lactose crystallization at industrially relevant concentrations by photon density wave spectroscopy. Chem Eng Technol. 2018:41:1139-46.

17. Häne J, Brühwiler D, Ecker A, Hass R. Real-time inline monitoring of zeolite synthesis by photon density wave spectroscopy. Microporous Mesoporous Mater. 2019:288:109580.

18. Bressel K, Müller W, Leser ME, Reich O, Hass R, Wooster TJ. Depletioninduced flocculation of concentrated emulsions probed by photon density wave spectroscopy. Langmuir. 2020;36:3504-13.

19. Gutschmann B, Schiewe T, Weiske MTH, Neubauer P, Hass R, Riedel SL. In-line monitoring of polyhydroxyalkanoate (PHA) production during high-cell-density plant oil cultivations using photon density wave spectroscopy. Bioengineering. 2019;6:85.

20. Pulz O, Broneske J, Waldeck P. IGV gmbh experience report, industrial production of microalgae under controlled conditions: innovative prospects. In: Richmond A, Hu Q, editors. Handbook of microalgal culture applied phycology and biotechnology. Chichester: Wiley; 2013. p. 445-60

21. Schreiber C, Behrendt D, Huber G, Pfaff C, Widzgowski J, Ackermann B, Müller A, Zachleder V, Moudříková Š, Mojzeš P, Schurr U, Grobbelaar J, Nedbal L. Growth of algal biomass in laboratory and in large-scale algal photobioreactors in the temperate climate of western Germany. Bioresour Technol. 2017;234:140-9,

22. Sandmann M, Smetana S, Heinz V, Rohn S. Comparative life cycle assessment of a mesh ultra-thin layer photobioreactor and a tubular glass photobioreactor for the production of bioactive algae extracts. Bioresour Technol. 2021;340:125657.

23. Hase E, Morimura Y, Tamiya H. Some data on the growth physiology of chlorella studied by the technique of synchronous culture. Arch Biochem Biophys. 1957:69:149-65.

24. Sandmann M, Lippold M, Saalfrank F, Odika CP, Rohn S. Multidimensional single-cell analysis based on fluorescence microscopy and automated image analysis. Anal Bioanal Chem. 2017;409:4009-19.

25. Garz A, Sandmann M, Rading M, Ramm S, Menzel R, Steup M. Cell-to-cell diversity in a synchronized chlamydomonas culture as revealed by singlecell analyses. Biophys J. 2012;103:1078-86.
26. Sandmann M, Garz A, Menzel R. Physiological response of two different Chlamydomonas reinhardtii strains to light-dark rhythms. Botany. 2015:94:53-64.

27. Graham MD. The coulter principle: foundation of an industry. J Assoc Lab Autom. 2003:8:72-81.

28. Wood WM, Lines RW. Particle size analysis using coulter counters. J Soc Cosmet Chem. 1966;17:197-211.

29. Hass R, Reich O. Photon density wave spectroscopy for dilution-free sizing of highly concentrated nanoparticles during starved-feed polymerization. Chem Phys Chem. 2011;12:2572-5.

30. Hass R, Munzke D, Ruiz SV, Tippmann J, Reich O. Optical monitoring of chemical processes in turbid biogenic liquid dispersions by photon density wave spectroscopy. Anal Bioanal Chem. 2015;407:2791-802.

31. Posten C. Design principles of photo-bioreactors for cultivation of microalgae. Eng Life Sci. 2009;9:165-77.

32. Luzi G, McHardy C, Lindenberger C, Rauh C, Delgado A. Comparison between different strategies for the realization of flashing light effects pneumatic mixing and flashing illumination. Algal Res. 2019;38:101404.

\section{Publisher's Note}

Springer Nature remains neutral with regard to jurisdictional claims in published maps and institutional affiliations.

Ready to submit your research? Choose BMC and benefit from:

- fast, convenient online submission

- thorough peer review by experienced researchers in your field

- rapid publication on acceptance

- support for research data, including large and complex data types

- gold Open Access which fosters wider collaboration and increased citations

- maximum visibility for your research: over $100 \mathrm{M}$ website views per year

At BMC, research is always in progress.

Learn more biomedcentral.com/submissions 